\title{
Acute stroke: low baseline blood pressure equals low seven-day life expectancy?
}

\author{
Acidente vascular cerebral agudo: pressão arterial baixa à admissão implica em redução \\ na expectativa de vida em 7 dias?
}

Tarun Girotra ${ }^{1}$, Bruce Ovbiagele ${ }^{2}$

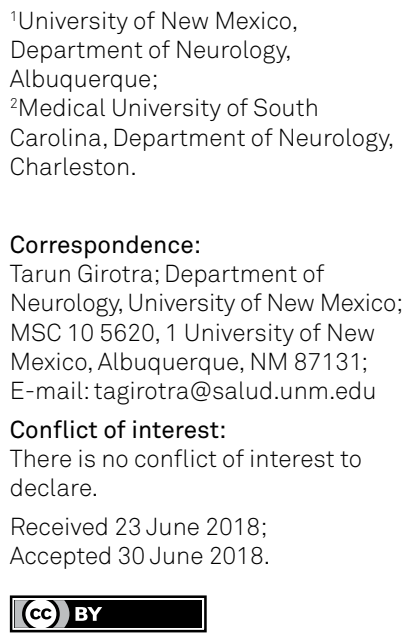

\section{(cc) BY}

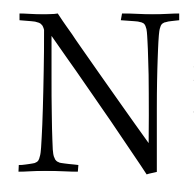

ormal cerebral autoregulation maintains uniform cerebral blood flow despite fluctuations in cerebral perfusion pressure between 50-150 $\mathrm{mm} \mathrm{Hg}$. This autoregulation is impaired during acute stroke resulting in a linear relationship between cerebral blood flow and cerebral perfusion pressure ${ }^{1}$. Elevated systolic blood pressure (SBP) and mean arterial pressure at presentation have been associated with poor outcomes, including early death ${ }^{1,2,3,4}$. There have been few studies that have also shown increased mortality with low SBP at baseline showing a U-shaped curve of mortality with blood pressure $^{1,5}$. These studies have been largely inclusive of minor and severe strokes and there is a paucity of research done to establish an association of mortality and acute blood pressure (BP) in high-risk patients.

In this issue of the journal, Furlan et al. ${ }^{6}$ report the findings of their single center study among 146 acute stroke patients admitted to the intensive care unit, which examined relationships between BP obtained at presentation and at 48-hours, and the occurrence of early mortality (within seven days). Among the 101 ischemic patients, they observed that baseline systolic BP, baseline diastolic BP, 48-hour mean systolic BP, and 48-hour mean diastolic BP were all significantly lower in patients who died within seven days compared with survivors; and in multiple regression analysis, the 48-hour mean systolic BP remained significantly associated with odds of early mortality. Moreover, a 48-hour mean systolic BP of $\leq 131 \mathrm{mmHg}$ was determined to be the most optimal cut-off for discriminating odds of early mortality. Among the 45 hemorrhagic stroke patients there were no significant associations between BP and occurrence of early mortality.

The authors are to be commended for investigating this important yet controversial issue, especially given the plethora of studies over the years that have sought to improve our understanding about how best to manage blood pressure for these patients, taking into consideration the different pathophysiology of the main stroke types (ischemic vs. hemorrhagic), and even subtypes (large vessel occlusion vs. small vessel ischemic disease). Nonetheless, the interpretation of findings observed among their ischemic stroke patients should be looked at carefully.

First, information about the various mechanisms of ischemic stroke was not available, although one may presume that since these were all critically ill patients requiring admission into the neurointensive care unit, chances are that the majority had large vessel occlusive disease (although patients with small vessel disease strokes and multiple comorbidities or newonset complications can also find themselves in a critical unit). Ischemic strokes secondary to large artery atherosclerosis may be more prone to hypoperfusion-related extension or recurrence of ischemic stroke than other etiologies of ischemic stroke. This phenomenon was noted in patients with ipsilateral (sub-group analysis of $\mathrm{SCAST}^{7}$ ) and bilateral severe carotid disease (meta-analysis of ECST, NASCET, and UK-TIA trial by Rothwell et al. ${ }^{8}$ ).

Second, was the difference between the baseline SBP and 48-hour mean SBP. The survivor group had a decline of $26 \mathrm{~mm} \mathrm{Hg}$ from baseline to 48-hour SBP whereas the difference was only $3 \mathrm{~mm} \mathrm{Hg}$ in the non-survivor group. Elevated blood pressure is common in the acute phase and can be seen in two-thirds to three-quarters of cases $^{9,10}$. The fact that the non-surviving group of ischemic strokes had uniformly low SBP in the first 48 hours may point towards an underlying hemodynamic confounder. While the authors did due diligence by performing the post hoc regression analysis to include possible confounders such as infection and myocardial 
infarction, they were unable to assess the potential impact of chronic or acute-on-chronic congestive heart failure due to limited information on cardiac function. Several community-based studies have shown that congestive heart failure is independently associated with greater mortality ${ }^{11-16}$ and undiagnosed congestive heart failure could have been the unaccounted-for confounder. Should oral antihypertensive medications that patients were using before stroke onset be temporarily held back or lowered in dose during acute ischemic stroke treatment to prevent inadvertent dramatic drops in BP? This is still not clear, but expert consensus guidelines recommend that the approach be individualized based on select patient and stroke features. However, beyond the initial 24-48 hours, it is not unreasonable to begin antihypertensive drug treatment given that the ischemic penumbra usually goes away within the initial 24 hours.

Third, the sample size is relatively small and the population is restricted to only patients admitted to the intensive care unit. In the case of the former (especially with intracerebral hemorrhage patients), the possibility of a type I error is high and in the case of the latter, the ability to generalize these findings to all stroke patients is questionable. Moreover, with hemorrhagic stroke, the low number of patients limits interpretation of the results. From the INTERACT- $2^{17}$ and ATACH- $2^{18}$ trials, we learned that achieving a target SBP of $140 \mathrm{~mm} \mathrm{Hg}$ acutely in intracerebral hemorrhage is safe and is possibly associated with improved outcomes, but targeting an SBP of $\leq$ $130 \mathrm{~mm} \mathrm{Hg}$ does not add any benefit while it increases the risk of renal complications. The mean 48-hour SBP in the surviving (143 mm Hg) and fatal (133 mm Hg) groups of hemorrhagic stroke patients were not overtly different from the target SBP achieved acutely in the active arm of the INTERACT-2 trial (139 mm Hg within six hours) and, hence, it is not surprising that no significant difference was found between the two arms of hemorrhagic stroke by Furlan et al. ${ }^{6}$.

Despite its limitations, the authors have identified an important sub-group of patients admitted to the intensive care unit with acute ischemic stroke. The presence of baseline and 48-hour mean SBP of $\leq 130 \mathrm{~mm} \mathrm{Hg}$ should be identified as a marker of poor outcomes, and carefully selecting such patients for further cardiac workup, such as echocardiography, should be done in centers with limited resources to identify and optimize the compromised hemodynamic state. In ischemic stroke, the current consensus-based guidelines recommend that there is no clear benefit in starting antihypertensive treatment in the acute setting after an ischemic stroke unless there is a strong indication to control elevated $\mathrm{BP}$ for a comorbid condition such as post-thrombolysis bleed or aortic dissection ${ }^{19}$. This study reinforces these guidelines and suggests it may not be appropriate to start antihypertensive agents within 48 hours in patients presenting with SBP of 130-140 mm Hg unless indicated for another reason.

\section{References}

1. Leonardi-BeeJ, Bath PM, Phillips SJ, Sandercock PA. Blood pressure and clinical outcomes in the International Stroke Trial.Stroke. 2002 May;33(5):1315-20. https://doi.org/10.1161/01.STR.0000014509.11540.66

2. Manning L, Hirakawa Y, Arima H, Wang X, Chalmers J, Wang $J$ et al. Blood pressure variability and outcome after acute intracerebral haemorrhage: a post-hoc analysis of INTERACT2, a randomised controlled trial. Lancet Neurol. 2014 Apr;13(4):364-73. https://doi.org/10.1016/S1474-4422(14)70018-3

3. Sare GM, Ali M, Shuaib A, Bath PM. Relationship between hyperacute blood pressure and outcome after ischemic stroke: data from the VISTA collaboration. Stroke. 2009 Jun;40(6):2098-103. https://doi.org/10.1161/STROKEAHA.108.539155

4. Geeganage C, Tracy M, England T, Sare G, Moulin T, Woimant F et al. Relationship between baseline blood pressure parameters (including mean pressure, pulse pressure, and variability) and early outcome after stroke: data from the Tinzaparin in Acute Ischaemic Stroke Trial (TAIST) [TAIST]. Stroke. 2011 Feb;42(2):491-3. https://doi.org/10.1161/STROKEAHA.110.596163

5. Vemmos KN, Tsivgoulis G, Spengos K, Zakopoulos N, Synetos A, Manios E et al. U-shaped relationship between mortality and admission blood pressure in patients with acute stroke.J Intern Med. 2004 Feb;255(2):257-65. https://doi.org/10.1046/j.1365-2796.2003.01291.x

6. Furlan NE, Bazan SGZ, Braga GP, Castro MCN, Franco RJS, Gut Al, et al. Association between blood pressure and acute phase stroke case fatality rate: a prospective cohort study. Arq Neuropsiquiatr. 2018 Jul;76(7):436-43. https://doi.org/10.1590/0004-282X20180059

7. Jusufovic M, Sandset EC, Bath PM, Karlson BW, Berge E. Effects of blood pressure lowering in patients with acute ischemic stroke and carotid artery stenosis. Int J Stroke. 2015 Apr;10(3):354-9. https://doi.org/10.1111/ijs.12418
8. Rothwell PM, Howard SC, Spence JD. Relationship between blood pressure and stroke risk in patients with symptomatic carotid occlusive disease. Stroke. 2003 Nov;34(11):2583-90. https://doi.org/10.1161/01.STR.0000094424.38761.56

9. Alqadri SL, Sreenivasan V, Qureshi Al. Acute hypertensive response management in patients with acute stroke. Curr Cardiol Rep. 2013 Dec;15(12):426. https://doi.org/10.1007/s11886-013-0426-7

10. Sare GM, Geeganage C, Bath PM. High blood pressure in acute ischaemic stroke: broadening therapeutic horizons. Cerebrovasc Dis. 2009;27 Suppl 1:156-61. https://doi.org/10.1159/000200454

11. Ois A, Cuadrado-Godia E, Jiménez-Conde J, Gomis M, Rodríguez-Campello A, Martínez-Rodríguez JE et al. Early arterial study in the prediction of mortality after acute ischemic stroke. Stroke. 2007 Jul;38(7):2085-9. https://doi.org/10.1161/STROKEAHA.107.482950

12. Petty GW, Brown RD Jr, Whisnant JP, Sicks JD, O'Fallon WM, Wiebers DO. Ischemic stroke subtypes: a population-based study of functional outcome, survival, and recurrence. Stroke. 2000 May;31(5):1062-8. https://doi.org/10.1161/01.STR.31.5.1062

13. Prosser J, MacGregor L, Lees KR, Diener HC, Hacke W, Davis S. Predictors of early cardiac morbidity and mortality after ischemic stroke. Stroke. 2007 Aug;38(8):2295-302. https://doi.org/10.1161/STROKEAHA.106.471813

14. Appelros P, Nydevik I, Viitanen M. Poor outcome after firstever stroke: predictors for death, dependency, and recurrent stroke within the first year. Stroke. 2003 Jan;34(1):122-6. https://doi.org/10.1161/01.STR.0000047852.05842.3C 
15. Divani AA, Vazquez G, Asadollahi M, Qureshi Al, Pullicino P. Nationwide frequency and association of heart failure on stroke outcomes in the United States. J Card Fail. 2009 Feb;15(1):11-6. https://doi.org/10.1016/j.cardfail.2008.09.001

16. Sharma JC, Fletcher S, Vasallo M, Ross I. Cardiovascular disease and outcome of acute stroke: influence of pre-existing cardiac failure. Eur J Heart Fail. 2000 Jun;2(2):145-50.

17. Anderson CS, Heeley E, Huang Y, Wang J, Stapf C, Delcourt C et al. Rapid blood-pressure lowering in patients with acute intracerebral hemorrhage. N Engl J Med. 2013 Jun;368(25):2355-65. https://doi.org/10.1056/NEJMoa1214609
18. Qureshi Al, Palesch YY, Barsan WG, Hanley DF, Hsu CY, Martin RL et al. Intensive Blood-Pressure Lowering in Patients with Acute Cerebral Hemorrhage. N Engl J Med. 2016 Sep;375(11):1033-43. https://doi.org/10.1056/NEJMoa1603460

19. Powers WJ, Rabinstein AA, Ackerson T, Adeoye OM, Bambakidis NC, Becker K et al. 2018 Guidelines for the Early management of patients with acute ischemic stroke: a guideline for healthcare professionals from the American Heart Association/ American Stroke Association. Stroke. 2018 Mar;49(3):e46-110. https://doi.org/10.1161/STR.00000000000000158 